\title{
Human Subject with Unexpected Biodistribution of $\left[{ }^{11} \mathrm{C}\right] \mathrm{PK} 11195$
}

\author{
Anne Roivainen ${ }^{*}, 1$ Kjell Någren ${ }^{2}$, Jere Virta $^{1}$ and Juha Rinne ${ }^{1}$ \\ ${ }^{I}$ Turku PET Centre, Turku University Hospital, FI-20521 Turku, Finland \\ ${ }^{2}$ Turku PET Centre, University of Turku, Radiopharmaceutical Chemistry Laboratory, FI-20500 Turku, Finland
}

\begin{abstract}
N-Methyl- $\left.{ }^{11} \mathrm{C}\right](\mathrm{R})-1-\left(2\right.$-chlorophenyl)-N-(1-methylpropyl)-3-isoquinoline carboxamide $\left[{ }^{11} \mathrm{C}\right] \mathrm{PK} 11195$ is a widely used radiopharmaceutical for in vivo assessment of translocator protein $18 \mathrm{kDa}$ (TSPO) activity using positron emission tomography. Here we present an interesting case of unusual distribution of $\left[{ }^{11} \mathrm{C}\right] \mathrm{PK} 11195$, that is a lack of uptake in tissues known for high expression of the TSPO.
\end{abstract}

Keywords: Translocator protein, PK11195, PET, carbon-11.

Positron emission tomography (PET) radiotracer $[N-$ methyl- $\left.{ }^{11} \mathrm{C}\right](R)$-1-(2-chlorophenyl)- $N$-(1-methylpropyl)-3-isoquinolinecarboxamide $\left(\left[{ }^{1} \mathrm{C}\right] \mathrm{PK} 11195\right)$ is a high-affinity ligand for the $18 \mathrm{kDa}$ translocator protein (TSPO), previously known as the peripheral benzodiazepine receptor (PBR). According to the available gene array datasets, the highest expression of TSPO is seen in the lungs and heart [1, 2]. At the cellular level, TSPO is expressed in monocyte/macrophage lineage cells and, within the central nervous system, in activated microglia, i.e. the brain-resident macrophages. Accordingly, $\left[{ }^{11} \mathrm{C}\right] \mathrm{PK} 11195$ has been used for in vivo visualization of TSPO and, thereby, the microglial activation in inflammatory brain diseases, such as, multiple sclerosis and amyotrophic lateral sclerosis $[3,4]$. Despite the widespread use of $\left[{ }^{11} \mathrm{C}\right] \mathrm{PK} 11195$ PET, the whole-body distribution and dosimetry of $\left[{ }^{11} \mathrm{C}\right] \mathrm{PK} 11195$ have not been studied until very recently $[2,5,6]$. Here, we report a case of atypical distribution of $\left[{ }^{11} \mathrm{C}\right] \mathrm{PK} 11195$.

The $\left[{ }^{11} \mathrm{C}\right] \mathrm{PK} 11195$ was prepared as described earlier [2]. The radiochemical purity was $99.9 \%$, and specific radioactivity was $32.8 \mathrm{MBq} / \mathrm{nmol}$ at the time of injection, as determined by radio-HPLC. Whole-body $\left[{ }^{11} \mathrm{C}\right]$ PK11195 PET imaging was performed on a healthy volunteer (male, age 23 years, height $180 \mathrm{~cm}$, weight $76 \mathrm{~kg}$ ) using an Advance PET scanner (General Electric Medical Systems, Milwaukee, WI, USA) operated in 2D mode. Imaging was performed with the subject in the supine position and arms alongside the body. The subject was intravenously injected with $704 \mathrm{MBq}$ of $\left[{ }^{11} \mathrm{C}\right] \mathrm{PK} 11195$, and the whole-body PET scanning proceeded from the head to the pelvic floor, excluding legs. Six bed positions were required for this measurement, with a 5-min acquisition time for each position. The acquired data were iteratively reconstructed, with attenuation correction, using ordered subset expectation maximization algorithm. Regions of interest were drawn on the areas of certain organs and

*Address correspondence to this author at the Turku PET Centre, Turku University Hospital, FI-20521 Turku, Finland; Tel: +358-2-3132862;

Fax: +358-2-2318191; E-mail. anne.roivainen@utu.fi

urinary bladder, followed by the calculation of the standardised uptake values $\left(\mathrm{SUV}_{\text {mean }}\right)$.
Whole-body PET images revealed an atypical biodistribution of radioactivity with enhanced uptake in the excretory and metabolic pathways (Fig. 1). Liver $\left(\mathrm{SUV}_{\text {mean }}\right.$ $1.94)$, vertebral column ( $\left.\mathrm{SUV}_{\text {mean }} 1.77\right)$, salivary glands $\left(\mathrm{SUV}_{\text {mean }} 1.67\right)$, thyroid gland, urinary bladder $\left(\mathrm{SUV}_{\text {mean }}\right.$ 1.49), hip bone, breast bone and small intestine $\left(\mathrm{SUV}_{\text {mean }}\right.$ 1.06) are clearly visible (arrows). However, the radioactivity uptake is very low in heart $\left(\mathrm{SUV}_{\text {mean }} 0.78\right)$, lungs $\left(\mathrm{SUV}_{\text {mean }}\right.$ 0.26 ) and kidneys, which normally have high densities of TSPO $[1,2]$.

It has been previously reported by our team [2, 5] and others $[6,7]$ that radioactivity after intravenous injection of $\left[{ }^{11} \mathrm{C}\right] \mathrm{PK} 11195$ is generally distributed in urinary bladder, adrenal gland, liver, salivary glands, heart, kidneys, and vertebral column. Poor radiochemical and chemical quality, or very low specific radioactivity could potentially be responsible for the atypical biodistribution of any radiotracer. However, in this case, both the radiochemical purity and the specific radioactivity were in line with our previous [ ${ }^{11} \mathrm{C}$ ]PK11195 studies ( $n=19$ subjects), with values $>99 \%$ and $35 \pm 9 \mathrm{MBq} / \mathrm{nmol}$, respectively $[2,5]$, and thus, they cannot explain the unexpected biodistribution findings. Furthermore, the subject had no significant prior medical history and was not on any medication at the time of the whole-body PET scan. Previously, however, Brown et al. have reported a similar unexpected distribution with another TSPO tracer, $\left[{ }^{11} \mathrm{C}\right]$ PBR28 [8]. In their study, one subject had decreased radioactivity uptake in organs with known high TSPO densities, i.e., brain, lungs, heart, spleen, and kidneys. Concordant with our finding with $\left[{ }^{11} \mathrm{C}\right] \mathrm{PK} 11195$, the heart, spleen, lungs, and kidneys could not be identified visually in this subject. The biodistribution was similar to that in a monkey with pre-blockade of receptors by means of high doses of nonradioactive PK11195.

In conclusion, in a larger study on a total of 19 human subjects, we observed unexpected whole-body biodistribution of $\left[{ }^{11} \mathrm{C}\right] \mathrm{PK} 11195$ in one subject. The reason for this atypical distribution remains unknown, but a low TSPO density is suggested as an explanation. 


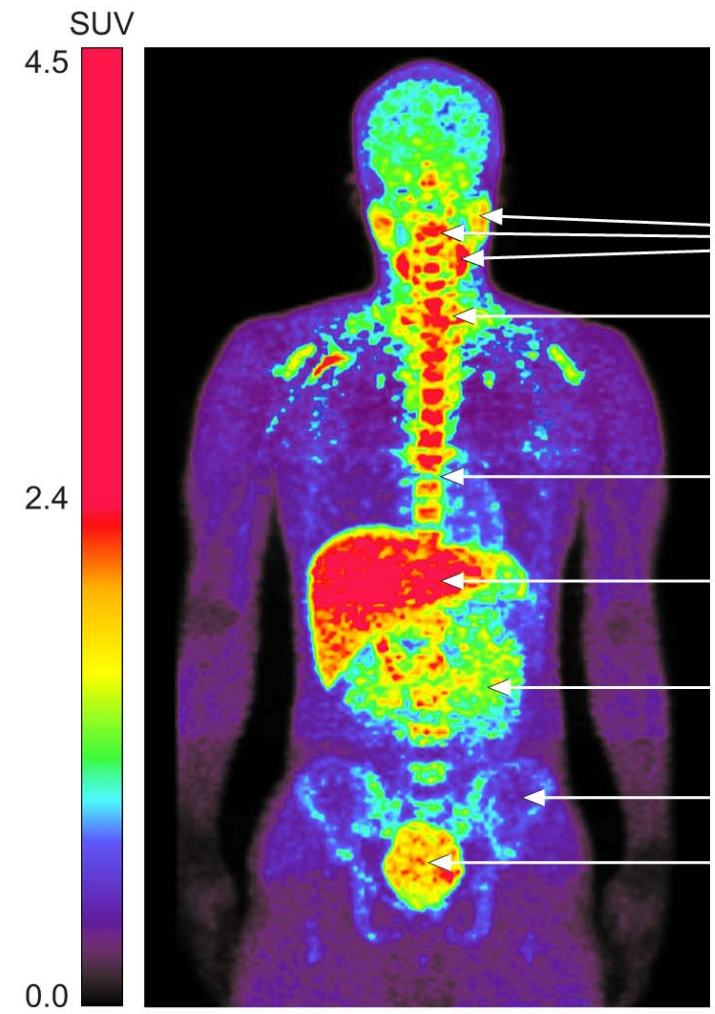

\section{Salivary glands}

Thyroid gland

Breast bone/ sternum

Vertebral column

Liver

Small intestine

Hip bone

Urinary bladder

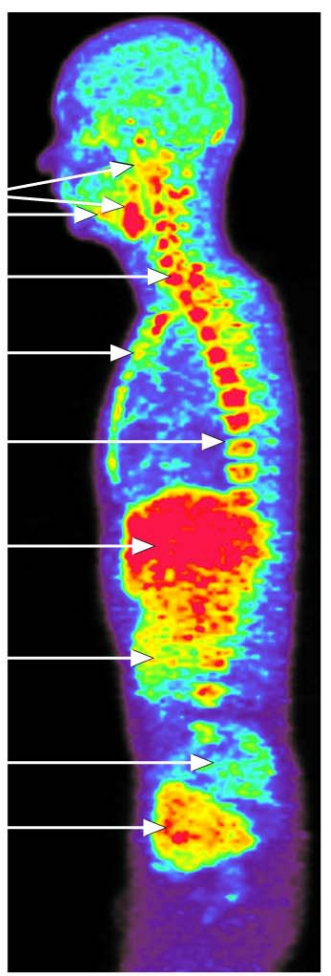

Fig. (1). PET scan of a healthy human subject with unexpected whole-body distribution of radioactivity after intravenous administration of $\left[{ }^{11} \mathrm{C}\right] \mathrm{PK} 11195$.

\section{REFERENCES}

[1] Huminiecki L, Lloyd AT, Wolfe KH. Congruence of tissue expression profiles from Gene Expression Atlas, SAGEmap and TissueInfo databases. BMC Genomics 2003; 4: 31.

[2] Roivainen A, Någren K, Hirvonen J, et al. Whole-body distribution and metabolism of [N-methyl-11C](R)-1-(2-chlorophenyl)-N-(1methylpropyl)-3-isoquinoline carboxamide in man: an imaging agent for in vivo assessment of peripheral benzodiazepine receptor activity with positron emission tomography. Eur J Nucl Med Mol Imaging 2009; 36: 671-82.

[3] Banati RB, Newcombe $\mathrm{J}$, Gunn $\mathrm{RN}$, et al. The peripheral benzodiazepine binding site in the brain in multiple sclerosis: quantitative in vivo imaging of microglia as a measure of disease activity. Brain 2000; 123: 2321-37.

[4] Turner MR, Cagnin A, Turkheimer FE, et al. Evidence of widespread cerebral microglial activation in amyotrophic lateral sclerosis: an $[11 \mathrm{C}](\mathrm{R})-\mathrm{PK} 11195$ positron emission tomography study. Neurobiol Dis 2004; 15: 601-9.

[5] Hirvonen J, Roivainen A, Virta J, Helin S, Någren K, Rinne JO. Human biodistribution and radiation dosimetry of $11 \mathrm{C}-(\mathrm{R})$ PK11195: the prototypic PET ligand to image inflammation. Eur J Nucl Med Mol Imaging 2010; 37: 606-12.

[6] Kumar A, Muzik O, Chugani D, Chakraborty P, Chugani HT. PETderived biodistribution and dosimetry of the benzodiazepine receptor-binding radioligand (11)C-(R)-PK11195 in children and adults. J Nucl Med 2010; 51: 139-44.

[7] Debruyne JC, Versijpt J, Van Laere KJ, et al. PET visualization of microglia in multiple sclerosis patients using [11C]PK11195. Eur J Neurol 2003; 10: 257-64.

[8] Brown AK, Fujita M, Fujimura Y, et al. Radiation dosimetry and biodistribution in monkey and man of 11C-PBR28: a PET radioligand to image inflammation. J Nucl Med 2007; 48: 2072-9.

(C) Roivainen et al.; Licensee Bentham Open.

This is an open access article licensed under the terms of the Creative Commons Attribution Non-Commercial License (http://creativecommons.org/licenses/by-nc/ 3.0/) which permits unrestricted, non-commercial use, distribution and reproduction in any medium, provided the work is properly cited. 